\title{
Comparison of the Floor and Infrared Radiant Heating System in Large-Space Buildings
}

\author{
Lizhi Jia $^{1}$, Junjie Liu ${ }^{* 1} \mathrm{Wu} \mathrm{Xiao}^{2}$, Haiqiao Zhang ${ }^{3}$, \\ ${ }^{1}$ Tianjin Key Laboratory of Indoor Air Environmental Quality Control, School of Environmental \\ Science and Engineering, Tianjin University, Tianjin, China. \\ ${ }^{2}$ China Aviation Planning and Design Institute (Group) CO., LTD, Beijing, China. \\ ${ }^{3}$ China Aviation International Construction and Investment Co., Ltd. (AVIC AIC), Beijing, China.
}

\begin{abstract}
Radiant heating system has been widely used in residential and office buildings due to its energy-saving and enhanced thermal comfort features. For large space building heating, there was no consistent answer. In this paper, the thermal and energy consumption performances of infrared radiant heating and floor, heating system in an aircraft hangar was compared using numerical simulation methods. The mean air temperature in the occupied zone, vertical temperature difference and energy efficiency of these two heating systems were analysed by Computational Fluid Dynamics (CFD) model, which was validated by the reported experimental results. The results indicated that both of the systems could meet the requirements of the design temperature. The temperature distribution of the floor radiant heating system was much uniform than that of the infrared radiant heating system in the aircraft hangar. With energy-utilization coefficient of 0.93 , the floor radiant heating system performed higher energy efficiency than that of infrared radiant heating. The energy consumption per floor per unit temperature difference for infrared radiant was nearly 1.5 times that of floor radiant heating system.
\end{abstract}

Keywords: Large space building; CFD; Vertical temperature difference; Energy -utilization coefficient

\section{Introduction}

With the development of the economy, an increasing number of large-space buildings have been built such as airport terminals, aircraft hangars and atriums. With large area of doors and windows and high height, large space buildings suffered huge amount of cold air infiltration or leakage and intrusion, resulting in large amount of heat load (Huang et al., 2007; Liu et al., 2018). Due to the high height, the air stratification and vertical temperature gradient were more serious than the others were, since the warm air gathered in the upper space of the building driven by the buoyancy force. This may cause large energy waste. Thus, special attention should be paid on the heating system design of large space building.

Radiant heating was considered as an alternative solution of the conventional heating system in large space building (ASHRAE, 2011). Radiant heating systems including infrared radiant (Han et al., 2014), ceiling panel heating (Ahmed et al., 2018), floor radiant heating and wall radiant heating (Koca and Cetin, 2017), transfer heat to the indoor environment mainly through thermal radiation.
To analysis the system performances, tools like Computational Fluid Dynamics (CFD) and energy simulation program usually were used in studies. Wang et al. (2018) improved the occupied zone thermal comfort by a secondary airflow device in a large enclosed space building using the CFD method. As compact and selfcontained heating devices, infrared heaters were applied in large buildings, such as hangars, factories, and warehouses (ASHRAE, 2011). The performance of Gasfired Infrared heating and convective heating system was compared by Han et al. (2014) using the CFD method. The result shown that natural gas infrared radiant heating could reduce the indoor air stratification and save over 10\% energy than convection heating system. And floor heating system has been proved to be that it could provide more uniform temperature distribution than the convective heating system in residential building (Risberg et al., 2015; Lin et al., 2016). The performance of different radiant panel heaters was compared by Seyam et al. (2014) using CFD method in parallel with experiment. Compared with wall and ceiling radiant heating, floor radiant heating system consumed the minimum energy with the same inside air temperature. Myhren and Holmberg (2008) investigated the characteristics of floor and wall heating system with different temperature level in two office rooms using an experimental validated CFD model. The results shown that lower radiant source temperature could provide a lower vertical air temperature difference.

In summary, comparison between infrared radiant heating and low-temperature floor heating system has not been seen in the previous studies. In this study, the performance of infrared radiant heating and low-temperature floor radiant heating system in an air hanger were compared under design condition. Several performance indexes were introduced to evaluate the temperature distribution and energy performance of different heating systems.

\section{Methods}

\section{Mathematical theory}

In this paper, the commercial program, Fluent, was adopted to calculate the indoor airflow and air temperature distribution in an aircraft hangar with different heating systems including infrared radiant heating and low-temperature floor heating system. The airflow and convective heat transfer are controlled by the governing equation of continue, momentum and energy equation, which can be described in a unified governing equation as Equation (1) (Chen and Srebric, 2002). 


$$
\frac{\partial \rho \emptyset}{\partial t}+\operatorname{div}(U \varnothing)=\operatorname{div}\left(\Gamma_{\varnothing} \operatorname{grad} \emptyset\right)+S_{\varnothing}
$$

where, $\emptyset$ represents any of the predicted variables; $U$ means the air velocity vector; $\Gamma_{\varnothing}$ is the diffusion coefficient; $S_{\varnothing}$ represents source.

In the indoor environment simulation field, the $\mathrm{k}-\varepsilon$, RNG turbulence model was generally used, which can obtain better results (Posner et al., 2014; Horikiri et al., 2011). For a room with radiant heating system, the radiation should be considered and calculated in the simulation, since the radiant heat transfer plays a key role in the radiant heating system. Discrete-Ordinates (DO) model can calculate not only the radiant transfer between surfaces (Seyam et al., 2014) but also radiant in medium (Raithby and Chui, 1990) Therefore, Do model was employed in the simulation. The governing equation of radiant heat transfer is shown as Equation (2) (Chui and Raithby, 1993).

$$
\begin{gathered}
\frac{d I(\vec{r}, \vec{s})}{d s}+\left(\alpha+\sigma_{s}\right) I(\vec{r}, \vec{s})=\alpha n^{2} \frac{\sigma T^{4}}{\pi}+ \\
\frac{\sigma_{s}}{4 \pi} \int_{0}^{4 \pi} I(\vec{r}, \vec{s}) \cdot \Phi(\vec{r}, \vec{s}) d \Omega^{\prime}
\end{gathered}
$$

where $\vec{r}$ is the position vector, $\vec{s}$ is the direction vector; $\alpha$ is the absorption coefficient; $\sigma_{s}$ is scattering coefficient; $\mathrm{n}$ is refractive index; $\sigma$ is Stefan-Boltzmann constant; $I$ is the radiation intensity; $T$ is the local temperature; $\Phi$ is phase function; $\Omega^{\prime}$ is the solid angle.

In addition, the buoyancy-driven natural ventilation in large-space building is a significant part of the heat transfer. To predict the indoor environment accurately, natural ventilation cannot be ignored. Boussinesq model treats density as a constant value in all solved equations except for the buoyancy term in the momentum equation. In buoyancy term, the density of the material varies approximately linearly with temperature.

\section{Performance evaluation}

To compare the system performance more intuitive, several dimensionless indexes are introduced including dimensionless temperature, energy-utilization coefficient and energy saving rate. They dimensionless temperature $\Theta(x, y, z)$ is defined as equation (3).

$$
\Theta(\mathrm{x}, \mathrm{y}, \mathrm{z})=\frac{T(x, y, z)-T_{\text {inlet }}}{T_{\text {outlet }}-T_{\text {inlet }}}
$$

Where, $T(x, y, z)$ is the air temperature of the point located at $(x, y, z) T_{\text {inlet }}$ and $T_{\text {outlet }}$ is the inlet and outlet air temperature of the building. In this paper, it represents the inlet and outlet of the Infiltration air temperature. The $\Theta(x, y, z)$ also reveals the uniformity of temperature distribution.

Reference to airflow performance index, Energyutilization coefficient of heating system was proposed. It is defined as Equation (4). It indicates the energy efficiency of the different heating system. A larger $\eta$ indicates higher energy efficiency of the system. If $T_{N}$ is higher than $T_{\text {ave }}$ and $\eta>1$, it shows that the heating system can transfer the heat to the occupant activity zone efficiently. On the contrary, $\eta \leq 1$ illustrates more heat is sent to the unoccupied zone and the efficiency of the heating system is low.

$$
\eta=\frac{T_{N}-T_{\text {out }}}{T_{\text {ave }}-T_{\text {out }}}
$$

where $T_{N}$ is the average temperature of the occupant activity zone; $T_{\text {out }}$ is the outdoor calculation temperature in heating season; $T_{a v e}$ is the indoor average temperature.

The third index is $\varphi$, which is defined as Equation (5). The $\varphi$ indicates the heat flow per floor area that should be supplied by the heating system to increase $1{ }^{\circ} \mathrm{C}$ of the occupied zone mean air temperature. Then the energy saving rate of the different heating systems $\Upsilon$ is defined as Equation (6).

$$
\begin{gathered}
\varphi=\frac{Q}{A_{\text {floor }\left(T_{N}-T_{\text {out }}\right)}} \\
\Upsilon=\frac{\varphi_{\text {Ir }}-\varphi_{\text {fl }}}{\varphi_{\text {Ir }}}
\end{gathered}
$$

where, $T_{N}$ is the average temperature of the occupied zone, in this study, the average temperature of $\mathrm{z}=1.5 \mathrm{~m}$ is used on behalf of $T_{N}$. $A_{\text {floor }}$ is the glass floor area of the building. $\varphi_{I r}$ and $\varphi_{f l}$ is the energy index of infrared radiant and floor heating system, respectively.

\section{Physical model and boundary conditions}

The aircraft hangar located in Beijing with $400 \mathrm{~m}$ in length, $100 \mathrm{~m}$ in width and $41 \mathrm{~m}$ in height. There are five aircrafts parked in the aircraft hangar. The physical model of the building is shown in Figure 1. To help the designer make a better choice, this study compared the natural gas tube infrared radiant heating and floor heating method in a large-space aircraft hangar. Figure 1 (a) shows the natural gas infrared radiant heating system. There were 82 radiant tubes suspended at a height of $31 \mathrm{~m}$. The surface temperature of the tube was calculated based on a separated tube model with $280{ }^{\circ} \mathrm{C}$ smoke sent in and the emission coefficient of the tube surface is 0.82 . The average surface temperature of tubes was $115^{\circ} \mathrm{C}$. Figure 1 (b) shows the floor heating system of the aircraft hangar. Due to sufficient insulation of the floor, it is assume that the heat loss of the floor can be ignored. The number of pipes, pipes' diameter and pipe type has little impact on system performance (Sattari and Farhanieh, 2006). As a reference control case, the floor surface temperature was calculated based on the heat conservation equation and the surface temperature of the floor was designed to be $25^{\circ} \mathrm{C}$. In large space buildings, the cold air infiltration is an important part of the heat load (Huang et al., 2007). Ten openings were evenly distributed on the bottom and top of the door to simulate the infiltration inlet and outlet. To compare the performance of these two heating methods, two cases were taken and the boundary conditions were summarised in Table 1. 


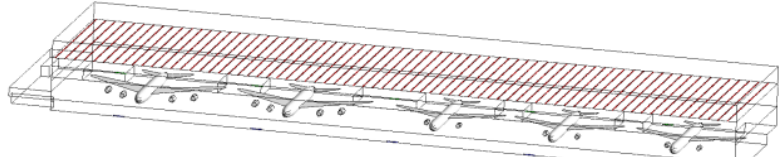

(a) Natural Gas Infrared Radiant Heating

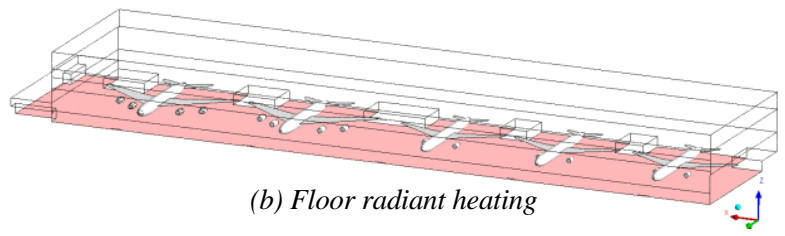

Figure 1: Physical models

Table 1: Boundary conditions of different cases

\begin{tabular}{|c|c|c|c|c|}
\hline $\begin{array}{c}\text { Boundary } \\
\text { Condition }\end{array}$ & $\begin{array}{c}\text { Heat } \\
\text { Source }\end{array}$ & $\begin{array}{c}\text { Infiltr } \\
\text { ation }\end{array}$ & Exterior Wall & $\begin{array}{c}\text { Inter } \\
\text { nal } \\
\text { Wall }\end{array}$ \\
\cline { 1 - 2 } $\begin{array}{c}\text { Infrared } \\
\text { Radiant }\end{array}$ & $\begin{array}{c}T_{\text {tube }}= \\
115^{\circ} \mathrm{C}\end{array}$ & \multirow{2}{*}{$\begin{array}{l}0.17 \\
\text { Floor- }\end{array}$} & $\begin{array}{c}h_{\text {wall }}=0.5 \mathrm{~W} /(\mathrm{m} 2 \mathrm{k}) \\
T_{\text {floor }}=2.0 \mathrm{~W} /(\mathrm{m} 2 \mathrm{k}) \\
h_{\text {window }}=3.0 \mathrm{~W} /(\mathrm{m} 2 \mathrm{k}) \\
h_{\text {roof }}=0.45 \mathrm{~W} /(\mathrm{m} 2 \mathrm{k}) \\
h_{\text {floor }}=0.4 \mathrm{~W} /(\mathrm{m} 2 \mathrm{k}) \\
t_{\text {out }}=-7.6^{\circ} \mathrm{C}\end{array}$ & $q=0$ \\
\cline { 1 - 2 } Heating & $25^{\circ} \mathrm{C}$ & & \\
\hline
\end{tabular}

\section{Results}

\section{Model validation}

Validation is very important to ensure reasonable results of CFD simulation. In this paper, the results of established CFD model have been compared with the experimental data (Olesen et al., 1980) and simulation results (Myhren and Holmberg, 2008). The detail physical model can be found in references. The commercial software, Fluent, was used to calculate the flow and temperature distribution of the environment chamber with the k- $\varepsilon$ turbulence model to calculate the flow due to cold air infiltration and the Boussinesq to simulate the natural convection due to the temperature difference. The Discrete Ordinates (Do) model was introduced to calculate the radiation heat transfer of the room. The indoor air temperature was calculated by the energy equation coupling the conventional and radiant heat transfer. The infiltration air change rate was $0.4 \mathrm{ACH}$, and outdoor air temperature is $-5{ }^{\circ} \mathrm{C}$. The heat transfer coefficient of external wall is $0.35 \mathrm{~W} /\left(\mathrm{m}^{2}\right.$. $\left.\mathrm{k}\right)$. The heat loss from the window was $224 \mathrm{~W}$, and there was no heat transported through the remaining walls. The average floor surface temperature is $26.5^{\circ} \mathrm{C}$. The simulation result was shown in Figure 1(a). From this chart, we can see that the CFD calculated result shows strong consistency with measured results in Olesen's work and simulation results in Myhren's works.

The Do model was also validated by the experimental data taken by Rousse et al. (2000). It was a two-dimensional square cavity radiation heat transfer issue. The floor temperature was $T_{w}$ and the temperature of the unheated walls was $0.5 T_{w}$. The simulated and tested indoor air temperature was normalised by the $T_{w}$, and it was shown in Figure 1(b). Obviously, the calculated result was in good agreement with the experiment data. Therefore, this method can be used for extended research.

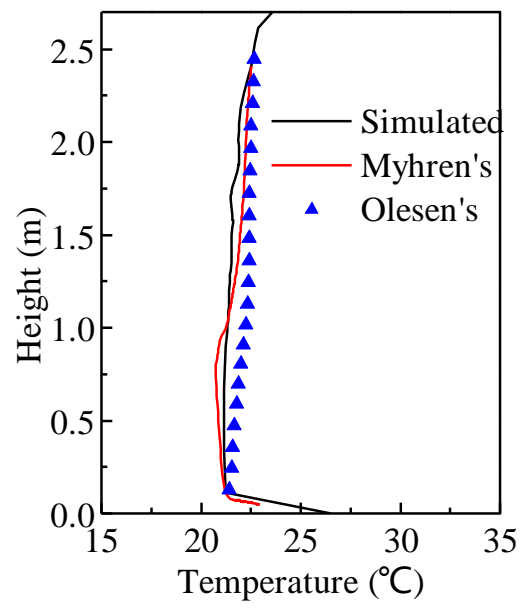

(a) CFD validation

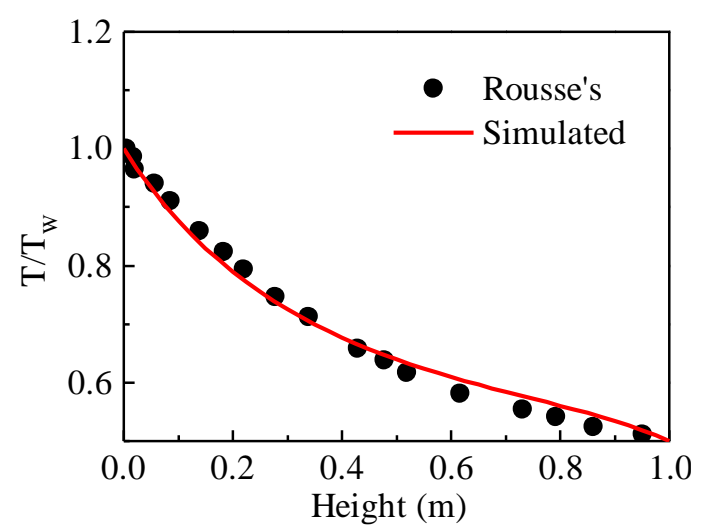

(b) Do model validation

Figure 1: Model validation results

\section{Temperature distribution}

The air temperature impacts the occupants' thermal comfort directly, especially air temperature in the occupied zone. In large buildings, such as aircraft hangars, the air temperature of the occupied zone is an important parameter to evaluate the performance of its air conditioning system. In this study, the temperature distribution of plane $1.5 \mathrm{~m}$ above the floor was selected to represent the occupied zone temperature distribution of the plane $1.5 \mathrm{~m}$ above the floor and the temperature distributions under different heating system have been compared. The results have been shown in Figure 2. When the building is heated by natural gas infrared radiant tubes, the average temperature of plane $\mathrm{z}=1.5 \mathrm{~m}$ is $18.7{ }^{\circ} \mathrm{C}$, which is higher than design indoor air temperature of $16{ }^{\circ} \mathrm{C}$. A floor heating system can provide an average temperature of $16.7^{\circ} \mathrm{C}$. Even though it is a little lower than the infrared radiant system, it also can satisfy the requirement of standards. From the picture, it can also be seen that the temperature distribution both systems is uniform except for the infiltration inlet area, which is a user-defined area to simulate the cold air infiltrate to the indoor environment. In a real project, the infiltration inlets distribute evenly around doors and windows. Therefore, 
the influence of infiltration inlet would be weaker than the simulation result in the infiltration inlet area and the temperature distribution would be more uniform in the real projects.

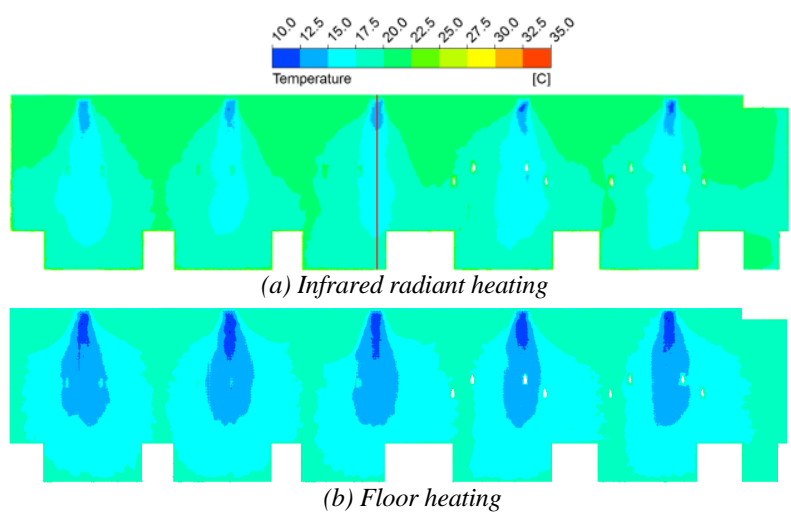

Figure 2: The temperature distribution of $z=1.5 \mathrm{~m}$

For further analysis of indoor temperature distribution, the dimensionless temperature $\Theta(\mathrm{x}, \mathrm{y}, \mathrm{z})$ at $\mathrm{z}=1.5 \mathrm{~m}$ was calculated, as shown in Figure 3. Overall, the dimensionless temperature of both systems ranged in a small scale, performing a uniform air distribution in horizontal plan. For the infrared radiant heating, the average $\Theta$ of the $\mathrm{z}=1.5 \mathrm{~m}$ plane is 0.56 , which means that mean temperature of $\mathrm{z}=1.5 \mathrm{~m}$ plane is lower the outlet air temperature. There were three main reasons. For one thing, in the infrared radiant system, the heat source locates at the height of $31 \mathrm{~m}$ and it approaches to the outlet of the leakage. For another thing, the high building height and strong thermal buoyancy enhances the air temperature of the outlet. In addition, the radiation from heat source gathered in the upper part of the space, because of the reflection from aircraft surface. Under the comprehensive effect of radiation and natural convection, the outlet air temperature is higher than the occupied zone air temperature. For the floor heating system, the mean dimensionless temperature of the plane $\mathrm{z}=1.5 \mathrm{~m}$ above the floor is 0.93 , close to 1 , which indicates that the occupied zone air temperature is close to outlet air temperature. As the heat source locates at the floor and the heat enters the occupied zone immediately. The thermal buoyancy can enhance the heat transfer to the upper space, and the temperature difference between occupied zone and outlet of the leakage can be reduced.

\section{Vertical temperature gradient}

In large space buildings, the vertical temperature gradient is a significant parameter concerned. In this section, the vertical temperature distribution and vertical temperature gradient of an aircraft hangar with different heating systems were analysed. Figure 4 shows the vertical temperature distribution of $y / L=0.5$. In Figure 4 (a), the air temperature of the lower parts of the aircraft space is a little higher than the design temperature $16^{\circ} \mathrm{C}$. The air temperature increases gradually along with the height of the position. The air temperature of the upper zone in the aircraft hangar is much higher than the occupied zone, especially the air above the radiant infrared radiant tubes. From Figure 4 (b), it can be seen that the air temperature of the infiltration area is low due to cold air infiltration. There is a very thin air layer with higher air temperature, which is just above the heating floor surface. Except for the two local areas mentioned above, the temperature distribution at other locations is uniform and ranges from 16.0 to $18.3^{\circ} \mathrm{C}$.

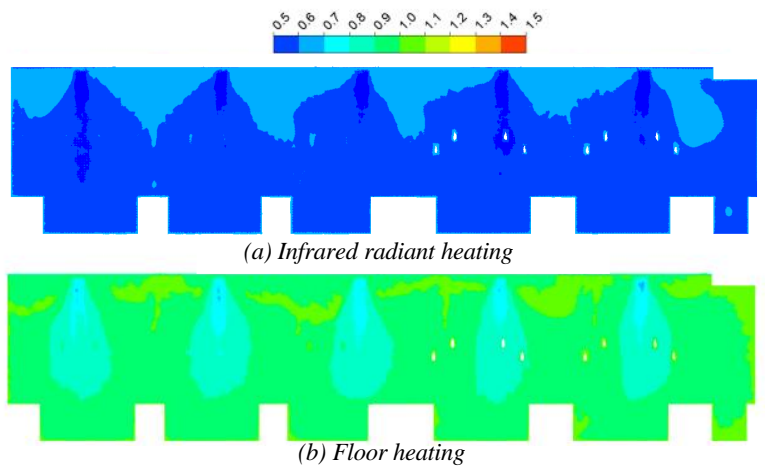

Figure 3: Dimensionless temperature distribution of $z=1.5 \mathrm{~m}$

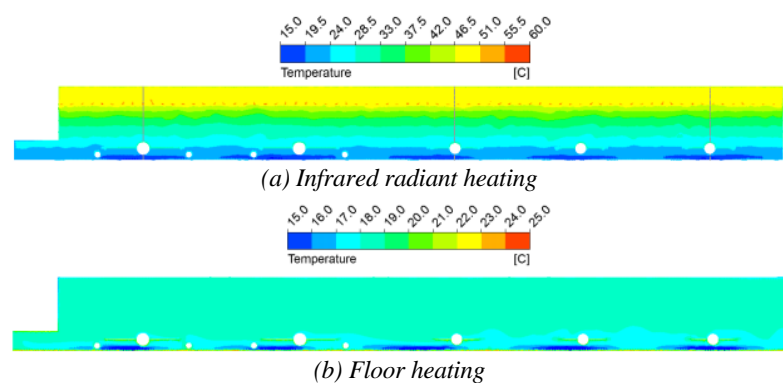

Figure 4: Vertical temperature distribution of $y / L=0.5$

For further analysis, three vertical lines were selected to represent different part of the space, as shown in Figure 4 (a). These lines go through the centre of the aircraft. The temperature variation of different positions was shown in Figure 5. For the infrared radiant heating system, the air temperature around the heat tube is highest, higher than $50^{\circ} \mathrm{C}$. The air temperature near the aircraft upper surfaces is higher than the around zones. Because the radiant heat from the radiant tubes transferred to the surface of the plane directly. The air around the top surfaces of aircrafts was heated by natural convection. Due to the reflection of the aircraft, the some of the radiation could not reach the floor surface, and the mean air temperature near the floor is lower than the surface temperature of the aircraft in infrared radiant heating. Overall, for the vertical temperature difference is larger, about $31^{\circ} \mathrm{C}$ and the vertical temperature gradient is $0.76^{\circ} \mathrm{C} / \mathrm{m}$. When the floor is considered as the heat source, the floor surface temperature is highest. Similar with the phenomenon near the upper surface of aircrafts, the air temperature near the floor surface was higher than the other spaces, since the air around the floor surface was heated through natural convention. The radiant heat transfer between the floor and surrounding surfaces including aircraft sufaces and walls is the main heat transfer method. Therefore, the walls' and aircraft bottom surfaces temperature is a little higher than the air temperature around the surfaces, as shown in Figure 5 (b). On the contrary, the top surface of 
aircrafts shows opposite trend due to the shade of aircraft. The air temperature of the zone above the aircrafts is almost the same. In comparison, the air temperature variation trend near the top surface of the aircraft is opposite in these two cases due to the location of the heat source. With $8.6^{\circ} \mathrm{C}$ vertical temperature difference, the floor heating system shows lower difference than that of the infrared radiant heating. The vertical temperature gradient is $0.21^{\circ} \mathrm{C} / \mathrm{m}$ for floor radiant heating system.

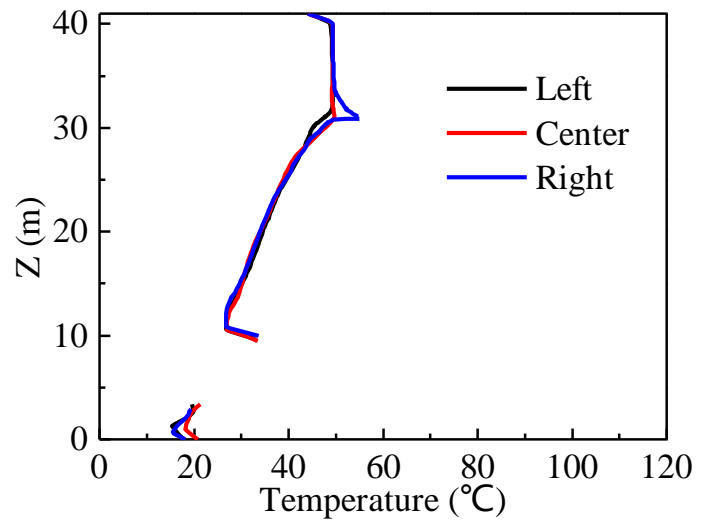

(a) Infrared radiant heating

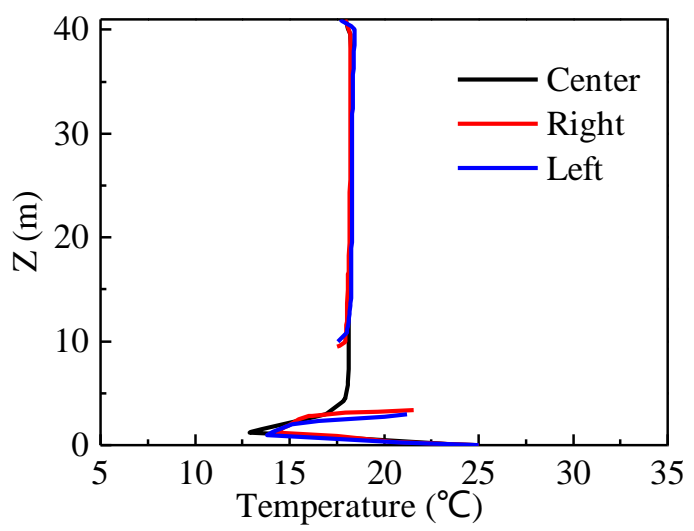

(b) Floor heating

Figure 5: Temperature of different positions

To compare these two systems, the dimensionless temperature $\Theta$ was introduced. Figure 6 indicates the $\Theta$ of the $y / L=0.5$ plane. From the picture, it can be seen clearly that the vertical temperature gradient of infrared radiant heating system is more serious than that of floor radiant heating system. The $\Theta$ of floor heating system is close to 1 , which indicates the temperature distribution is approach to be uniform.

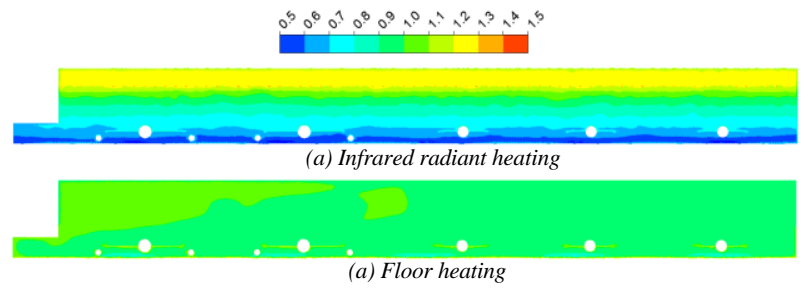

Figure 6: The vertical dimensionless temperature distribution of $y / L=0.5$

The average dimensionless air temperature of different heating systems was shown in Figure 7. It can be seen that the floor heating system vertical dimensionless temperature is close to 1 , except for the local area above the floor surface. The vertical gradient is 0.66 for the infrared radiant heating system. For floor radiant heating system, the vertical temperature gradient is 0.33 . The vertical temperature gradient of an infrared radiant heating system is about 2 times higher than that of a floor heating system in the aircraft hangar.

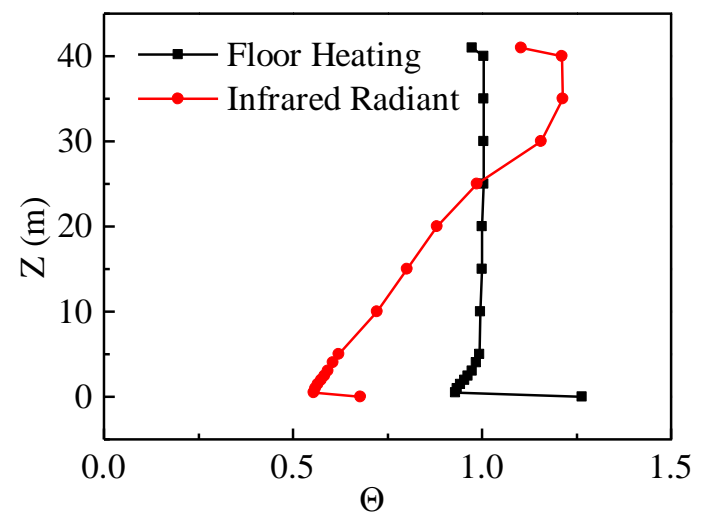

Figure 7: Average temperature of different height planes.

\section{Energy consumption index}

Energy performance of the heating system is another important factor that influences the decision of designers. The analysis above shows that the indoor air temperature distribution is different with different heating systems. In this section, the energy consumption index $\eta, \varphi$ were calculated to evaluate different heating systems, as shown in Figure 8. The energy-utilization coefficient of infrared radiant heating system is 0.61 and it is 0.93 for a floor heating system. Obviously, the floor heating system shows higher energy efficiency than that of the infrared radiant heating system in the aircraft hangar. It is because of that the floor radiant heating system directly supplies heat to the occupied zone through radiant and conventional heat transfer. However, infrared radiant tube which is located at the height of $31 \mathrm{~m}$ was shaded by the air plane and part of the radiant heat was reflected back to the upper space. The energy consumption index $\varphi$ of infrared radiant heating system is $6.8 \mathrm{~W} /\left(\mathrm{m}^{2} \cdot \mathrm{K}\right)$ and it is 1.5 times higher than the floor heating $\operatorname{system}\left(4.4 \mathrm{~W} /\left(\mathrm{m}^{2} \cdot \mathrm{K}\right)\right)$. It indicates more energy is needed to be supplied by the infrared radiant heating system. system to maintain the occupied zone air temperature at the same design value Finally, the energy saving rate of the floor heating system compared with infrared radiant heating system can be calculated according to Equation (6) and the $\Upsilon$ is $35.3 \%$. 


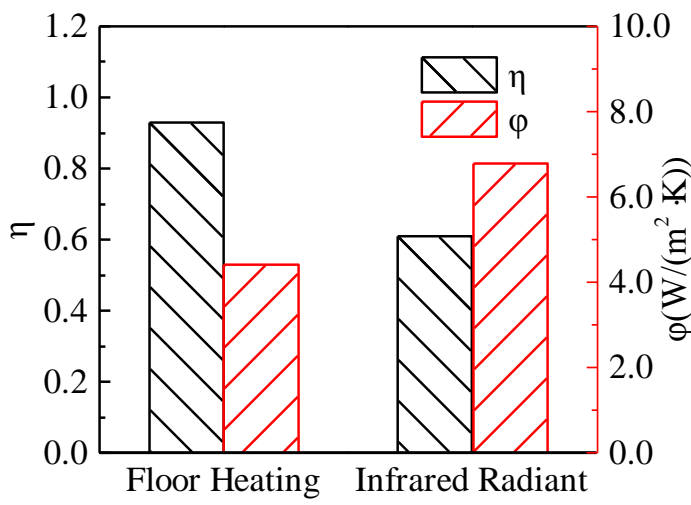

Figure 8: Energy consumption index of different heating methods.

\section{Discussion}

From the analyses above, it can be found that the floor heating system shows good performance both in temperature distribution and energy performance. However, there was something others should be noticed when designers choose a floor heating system in largespace buildings. The floor radiant heating system embeds water pipes into the floor. When the floor heating system installation is completed, works of drilling on the floor should be avoided. Second, the floor heating system has strong thermal inertia and it is not convenient for adjustment or intermittent operation, which may cause water freezing issues. For the infrared radiant heating system, the surface temperature of tubes is high and it must be installed at a high position to avoid cause burns, safety issues and thermal uncomfortable. Compared with the floor heating system, the infrared radiant tubes are easy to control and it suits for intermittent operation or local heating.

\section{Conclusion}

This study compared the temperature distribution and energy performance of an infrared radiant heating and a floor heating system in an aircraft hangar. From the analysis above, the following conclusions can be obtained. In large space buildings, both infrared radiant and floor heating system can satisfy the design temperature requirement of standards and uniform temperature distribution in horizontal plane of the occupied zone. However, the vertical temperature distribution is less uniform, especially the infrared radiant heating system. The vertical temperature difference of infrared radiant heating system is about 2 times higher than floor radiant heating. With the energy-utilization coefficient of 0.93 , the floor heating system shows higher energy efficiency and the saving rate was $35.3 \%$.

In summary, compared with infrared radiant heating, the floor heating system can provide more uniform temperature distribution and higher energy utilization rate.

\section{Acknowledgement}

The research in this paper was supported by the National Key R\&D Program of the Ministry of Science and
Technology, China, on "Green Buildings and Building Industrialization" through Grant No. 2018YFC0705304.

\section{References}

Ahmed, K., E. Sistonen, R. Simson, J. Kurnitski, J. Kesti, and P. Lautso. (2018). Radiant panel and air heating performance in large industrial buildings. Building Simulation, 11 (2):293-303.

ASHRAE. (2011). ASHRAE Handbook--HVAC Application(SI). Atlanta, GA(US).

Chen, Q., and J. Srebric. (2002). A Procedure for Verification, Validation, and Reporting of Indoor Environment CFD Analyses. HVAC\&R Research, 8 (2):201-216.

Chui, E. H., and G. D. Raithby. (1993). Computation of radiant heat transfer on a nonorthogonal mesh using the finite-volume method. Numerical Heat Transfer, Part B: Fundamentals, 23 (3):269-288.

Han, Y. M., Z. W. Li, and P. Xu. (2014). Comparative Study on Energy Consumption of Gas-Fired Infrared Radiant and Convection Heating. Advanced Materials Research, 953-954:849-853.

Horikiri, K., Y. Yao, and J. Yao. (2011). Steady-State Natural Convection in Empty and Partitioned Enclosures at High Rayleigh Numbers. International Journal of Energy and Environment, 1 (5):574-581.

Huang, C., Z. Zou, M. Li, X. Wang, W. Li, W. Huang, J. Yang, and X. Xiao. (2007). Measurements of indoor thermal environment and energy analysis in a large space building in typical seasons. Building and Environment, 42 (5):1869-1877.

Koca, A., and G. Çetin. (2017). Experimental investigation on the heat transfer coefficients of radiant heating systems: Wall, ceiling and wall-ceiling integration. Energy and Buildings, 148:311-326.

Lin, B., Z. Wang, H. Sun, Y. Zhu, and Q. Ouyang. (2016). Evaluation and comparison of thermal comfort of convective and radiant heating terminals in office buildings. Building and Environment, 106:91-102.

Liu, X., L. Lin, X. Liu, T. Zhang, X. Rong, L. Yang, and D. Xiong. (2018). Evaluation of air infiltration in a hub airport terminal: On-site measurement and numerical simulation. Building and Environment, 143:163-177.

Myhren, J. A., and S. Holmberg. (2008). Flow patterns and thermal comfort in a room with panel, floor and wall heating. Energy and Buildings, 40 (4):524-536.

Olesen, B. W., E. Mortensen, J. Thorshauge, and B. Berg. Munch. (1980). Thermal comfort in a room heated by different methods. ASHRAE Transactions:34-47.

Posner, J. D., C. R. Buchanan, and D. Dunn-Rankin. (2014). Measurement and prediction of indoor air flow in a model room. Energy and Buildings, 35 (5):515526. 
Raithby, G. D., and E. H. Chui. (1990). A Finite-Volume Method for Predicting a Radiant Heat Transfer in Enclosures With Participating Media. Asme Transactions Journal of Heat Transfer, 112 (2):415423.

Risberg, D., M. Vesterlund, L. Westerlund, and J. Dahl. (2015). CFD simulation and evaluation of different heating systems installed in low energy building located in sub-arctic climate. Building and Environment, 89:160-169.

Rousse, D. R., G. Gautier, and J. Sacadura. (2000). Numerical predictions of two-dimensional conduction, convection, and radiation heat transfer. II. Validation.
International Journal of Thermal Sciences, 39 (3):332-353.

Sattari, S., and B. Farhanieh. (2006). A parametric study on radiant floor heating system performance. Renewable Energy, 31 (10):1617-1626.

Seyam, S., A. Huzayyin, H. El-Batsh, and S. Nada. (2014). Experimental and numerical investigation of the radiant panel heating system using scale room model. Energy and Buildings, 82:130-141.

Wang, H., C. Huang, Y. Cui, and Y. Zhang. (2018). Experimental study on the characteristics of secondary airflow device in a large enclosed space building. Energy \& Buildings, 166:347-357. 